\title{
Circling Behavior Following Unilateral Microinjections of Cocaine into the Medial Prefrontal Cortex: Dopaminergic or Local Anesthetic Effect?
}

\author{
Michel A. Morency, Robert J. Stewart, and Richard J. Beninger \\ Department of Psychology, Queen's University, Kingston, Ontario K7L 3N6, Canada
}

\begin{abstract}
Dopaminergic projections to the medial prefrontal cortex have been implicated in cocaine reinforcement; therefore, it was of interest to examine the locomotor effects of acute administration of cocaine to this area. Circling behavior was assessed following injections of $1.0 \mu \mathrm{l}$ of cocaine in doses of $0(0.9 \%$ saline $), 25,50$, and $100 \mu \mathrm{g} / \mu \mathrm{l}$ into the medial prefrontal cortex of rats prepared with chronic unilateral guide cannulae. Animals were scored during four $5 \mathrm{~min}$ intervals of a $60 \mathrm{~min}$ test session that began with the central injection and placement in a flat circular arena. Cocaine was found to produce dose-dependent contraversive circling, an effect previously seen with the dopamine (DA) agonists LY 141865 and $(+)$-amphetamine, suggesting a unilateral stimulant effect. However, since cocaine has potent local anesthetic properties that have been reported to produce behavioral effects and also to inhibit the reuptake of norepinephrine and 5- $\mathrm{HT}$, it was important to demonstrate that the directional bias was a dopaminergic effect. Intrafrontocortical microinjections of the local anesthetic procaine $(10,100$, and $1000 \mu \mathrm{g}$ in $0.5 \mu \mathrm{l})$ did not induce circling. Sulpiride (0.001-10.0 $\mu \mathrm{g}$ in 0.5 $\mu \mathrm{l})$, a DA antagonist specific for the D-2 receptors, produced ipsiversive circling in a dosedependent manner in rats treated with ( + )-amphetamine (1.5 $\mathrm{mg} / \mathrm{kg}, \mathrm{i} . \mathrm{p}$.). In addition, sulpiride (1.0 $\mu \mathrm{g}$ in $0.5 \mu \mathrm{l})$ blocked the circling behavior induced by cocaine $(50 \mu \mathrm{g}$ in $0.5 \mu \mathrm{l})$ when administered into the medial prefrontal cortex $15 \mathrm{~min}$ prior to the cocaine injection. These results provide further evidence for an excitatory influence of mesocortical DA on motor control.
\end{abstract}

The central neurotransmitter dopamine (DA) has clearly been shown to influence locomotor activity (Beninger, 1983; Joyce, 1983). Elevation of DA function produces an enhancement of motor activity (Costall and Naylor, 1975; Jackson et al., 1975; Pijnenberg et al., 1976); conversely, decreasing DA neurotransmission produces hypoactivity (Anden et al., 1970). Circling behavior resulting from unilateral manipulation of central DA

\footnotetext{
Received Apr. 10, 1986; revised Aug. 7, 1986; accepted Sept. 8, 1986.

Sulpiride and $(+)$-amphetamine were the generous gifts of Delagrange International and Smith Kline and French Canada Ltd., respectively. This research was supported by grants from the Natural Sciences and Engineering Research Council of Canada and the Ontario Ministry of Health to R.J.B. The excellent technical assistance of A. T. A. Korda and F. H. Gouzoules is gratefully acknowledged.

Correspondence should be addressed to Michel Morency at his present address: Departments of Psychiatry and Neurosciences, Health Science Centre, Rm. 4N52, McMaster University, Hamilton, Ontario L8N 3Z5, Canada.

Copyright @ 1987 Society for Neuroscience $0270-6474 / 87 / 030812-07 \$ 02.00 / 0$
}

has commonly been used to assess this neurotransmitter's contribution to motor control (Anden et al., 1969); animals characteristically circle away from (contralateral to) the side of higher DA activity. Although this approach has provided extensive evidence for the contribution of nigrostriatal and mesolimbic DA systems to motor activity (Pycock, 1980), the involvement of the mesocortical DA system is poorly understood.

Cortical DA projections have received much attention since their first biochemical demonstration (Thierry et al., 1973). Substantial evidence exists to suggest that frontal cortical DA has a functional neurotransmitter role. Specifically, a DA-sensitive adenylate cyclase has been discovered in this area (Ahn et al., 1976), neuroleptic binding sites have been found (Fields et al., 1977), and DA release from the frontal cortex has been recorded in vitro (Saldate and Orrego, 1977) and in vivo (Myers and Mora, 1977).

Although biochemical evidence favors a transmitter role for DA in the frontal cortex, there have been relatively few attempts to correlate changes in cortical DA function with behavior. Initial studies have suggested that frontal cortical DA has a role opposite to its counterpart in mesolimbic or extrapyramidal DA areas (Carter and Pycock, 1978), where DA-dependent hyperactivity and stereotypy are believed to be mediated (Costall et al., 1977). The inhibitory role initially ascribed to frontal cortical DA stemmed from 6-hydroxydopamine (6-OHDA) studies demonstrating that frontal cortical DA depletion produced hyperactivity after a period of 7-10 d (Pycock et al., 1980a; Robinson and Stitt, 1981; Joyce et al., 1983). Further support for this hypothesis was provided by the finding of a high correlation between the increase in locomotor activity and decrease in frontal cortical DA levels $30 \mathrm{~d}$ after bilateral electrolytic destruction of the ventral tegmental area (Tassin et al., 1978). However, biochemical data demonstrated that, 4 weeks after frontal cortical DA denervation, there was an increase in DA function and utilization in subcortical areas (Pycock et al., 1980b). Therefore, while lesioning cortical DA may have released its putative tonic inhibition of motor activity, it is also possible that the locomotor hyperactivity was the consequence of these time-dependent subcortical changes.

By employing an acute manipulation of frontal cortical DA neurotransmission, the contribution of this system to motor control was assessed independently of compensatory changes in the sensitivity of subcortical DA systems. Thus, in our laboratory, circling behavior has been induced by acute unilateral microinjections of dopaminergic agents into the medial prefrontal cortex of rats. Two agonists, $(+)$-amphetamine and $L Y$ 141865 , and 2 antagonists, metoclopramide and sulpiride (SUL), 
produced contraversive and ipsiversive circling, respectively (Morency et al., 1985; Stewart et al., 1985). These results suggest an excitatory influence of frontal cortical DA on motor control; if DA played an inhibitory role in the frontal cortex, it then follows that rats would have circled towards the side of higher DA activity, as this side would have been the locus of greater motor inhibition.

Cocaine is an indirect agonist that inhibits the reuptake of DA (Snyder and Coyle, 1969; Heikkila et al., 1979), norepinephrine (NE) (Langer and Enero, 1974), and 5-HT (Ross and Renyi, 1967). The rewarding effects of cocaine reinforcement have been demonstrated to be mediated, in part, by mesocortical DA projections to the medial prefrontal cortex (Goeders and Smith, 1983). Reward influences behavior by increasing the incentive value of environmental stimuli that, by definition, have an enhanced ability to influence response systems (Bindra, 1978; Beninger, 1983; Willner, 1983). Thus, it was of interest to determine whether unilateral microinjections of cocaine into this DA terminal area would produce circling.

\section{Materials and Methods}

Animals. Male albino Wistar rats weighing 200-250 gm were obtained from Charles River Canada. Animals were individually housed in a climatically controlled $\left(21 \pm 1^{\circ} \mathrm{C}\right)$ colony room on a $12 \mathrm{hr}$ light $(0600-$ $1800) /$ dark cycle. Food and water were continuously available in the home cages.

Surgeries. All rats were anesthetized with sodium pentobarbital (Somnotol), $60 \mathrm{mg} / \mathrm{kg}$, i.p. The animals were prepared with chronic indwelling stainless steel guide cannulae ( 23 gauge) stereotaxically implanted in the medial prefrontal cortex at the following coordinates: $4.5 \mathrm{~mm}$ anterior to bregma, $0.7 \mathrm{~mm}$ lateral to the midline, and $1.0 \mathrm{~mm}$ ventral to the dura mater, with the incisor bar set $5.0 \mathrm{~mm}$ above the interaural line (Pellegrino et al., 1979). Cannulae were anchored to the skull with stainless steel screws and acrylic cement. They were sealed between injections with stainless steel oblurator pins secured with silicone. Eighteen rats were cannulated for each experiment; cannulae were implanted into the left frontal cortex of half the animals and into the right frontal cortex of the others.

Apparatus. Three polyurethane-sealed circular wooden bases, $30 \mathrm{~cm}$ in diameter, enclosed within a cylinder of wire mesh $30 \mathrm{~cm}$ high, were fitted with Plexiglas covers.

Drugs. Cocaine hydrochloride (BDH Chemicals, Toronto), (+)-amphetamine sulfate (Smith Kline and French), and procaine hydrochloride (Sigma Chemical Co.) were dissolved in distilled water. Sulpiride (Delagrange) was dissolved in a minimal amount of $0.5 \mathrm{~N} \mathrm{HCl}$, neutralized with $0.5 \mathrm{~N} \mathrm{NaOH}(\mathrm{pH} 7.0-7.5)$, and made up to volume with distilled water. All drugs were dissolved daily, prior to behavioral testing.

Central injections. Manual intrafrontocortical microinjections of the drug or the vehicle were delivered by a $5 \mu \mathrm{l}$ Hamilton microsyringe. Injection cannulae were constructed with 30 gauge stainless steel tubing cut to extend $1.0 \mathrm{~mm}$ beyond the tip of the guide cannula and attached to the microsyringe by a length of polyethylene tubing. The injection was delivered in 15-30 sec and the injection cannula left in place for an additional $60 \mathrm{sec}$ to ensure sufficient diffusion and avoid withdrawing of the drug during removal of the injection system. The obturator pin was then reinserted into the guide cannula and secured with sealant.

Behavioral testing. Testing began approximately $7 \mathrm{~d}$ after surgery. Each animal was tested 7 times as follows: (1) no central injection; (2) central injection of the vehicle; (3) each of the 3 drug doses with order of administration counterbalanced across rats over 3 sessions; (4) replication of vehicle; (5) replication of no central injection (this last test session was not performed in the first experiment). Three days were allowed between test sessions for each animal. A test session began with the intracerebral injections and placement in the circular arena.

All complete turns $\left(360^{\circ}\right)$, ipsiversive and contraversive to the side of the cannulae, were counted during each observation period. Three animals were scored during each 60 min session, observation periods being at $0-5,15-20,30-35$, and $45-50 \mathrm{~min}$. The clock was stopped during the time taken to administer the central injections (maximum of $2 \mathrm{~min}$ ). Animals were started at staggered intervals of 5 min such that only 1 animal was being scored at any time. Thus, each animal was scored for a total of $20 \mathrm{~min}$, in four 5 min blocks at approximately equal intervals throughout a 60 min session.

Circling behavior was expressed as the ratio of ipsiversive turns to the total number of turns (ipsiversive + contraversive). Ratio values of 0.5 indicated equal turning in both directions. Values greater or less than 0.5 indicated a tendency for ipsiversive (toward the side of the central injection) or contraversive (away from the side of the central injection) circling, respectively. The total number of turns per session (ipsiversive + contraversive) served as the second dependent measure.

Histolngy. At the conclusion of behavioral testing, animals were sacrificed for histological confirmation of cannula placements (Fig. 1). Rats were injected with an overdose of sodium pentobarbital, exsanguinated, and perfused intracardially with $10 \%$ formalin. Frozen coronal sections $(40 \mu \mathrm{m})$ were taken through the frontal cortex, mounted, and stained with thionin (Donovick, 1974).

Statistical analyses. For all experiments, an arcsine transformation was conducted on the ratio data to satisfy the assumptions of the analysis of variance (ANOVA). For the turning ratio and total turns data, $t$ tests for correlated measures were conducted on the first and second noinjection scores, as well as the first and second vehicle scores. Onefactor, repeated measures ANOVAs were used to analyze drug effects (including the no-injection and vehicle conditions). Individual comparisons of the turning ratio data were made with planned post hoc comparisons and ANOVAs.

\section{Results}

The numbers of rats included in the statistical analyses for the 5 experiments were $12,12,11,11$, and 14 , respectively. The remaining rats were discarded due to defective cannulae or inaccurate placements. It is important to note that the discarded animals with placements lateral to the target area $(n=3)$ failed to circle in response to drug treatments. The cannulae placements are illustrated in Figure 1.

\section{Experiment 1: cocaine-induced circling behavior}

The purpose of this experiment was to determine whether unilateral microinjections of cocaine into the medial prefrontal cortex would produce circling. Manual injections of $1.0 \mu \mathrm{l} \mathrm{co-}$ caine hydrochloride were delivered at doses of $0(0.9 \%$ saline $)$, 25,50 , and $100 \mu \mathrm{g} / \mu \mathrm{l}$.

A $t$ test for correlated measures of the turning ratio data for the first and second saline test session scores revealed no significant difference. Consequently, each animal's scores from these 2 sessions were combined for subsequent analyses.

As shown in Figure $2 A$, the no-injection, saline, and $25 \mu \mathrm{g}$ dose produced turning ratios of approximately 0.5 , indicating no directional bias. The 50 and $100 \mu \mathrm{g}$ doses produced markedly lower turning ratios, indicating a contraversive bias. A onefactor, repeated-measures ANOVA confirmed a significant dose effect $[F(4,44)=12.79, p<0.0001]$. Planned comparisons revealed no significant difference between the no-injection and saline conditions. The $25 \mu \mathrm{g}$ turning ratio was higher than the combined 50 and $100 \mu \mathrm{g}$ ratios $[F(1,11)=42.35, p<0.0005]$, the latter two not differing significantly. Both the 50 and 100 $\mu \mathrm{g}$ turning ratios were significantly lower than saline (Fig. $2 A$ ).

The mean number ( \pm SEM) of total turns per session for each dose of cocaine was as follows: no-injection, $10.5( \pm 1.1)$; saline, $13.8( \pm 0.6) ; 25 \mu \mathrm{g}, 14.3( \pm 1.1) ; 50 \mu \mathrm{g}, 20.7$ ( \pm 1.1$) ; 100 \mu \mathrm{g}, 21.1$ $( \pm 1.6)$. A one-factor, repeated measures ANOVA revealed a significant dose effect $[F(4,44)=15.70, p<0.0001]$.

The strong tendency for contraversive circling observed following the 50 and $100 \mu \mathrm{g}$ doses suggests that cocaine produced an ipsilateral enhancement of locomotor activity. This directional bias is consistent with a stimulant effect of cocaine. The 
A

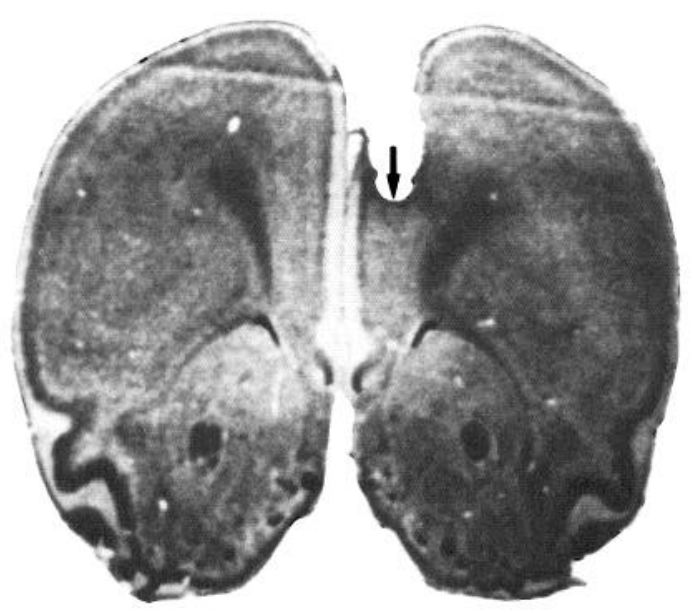

B
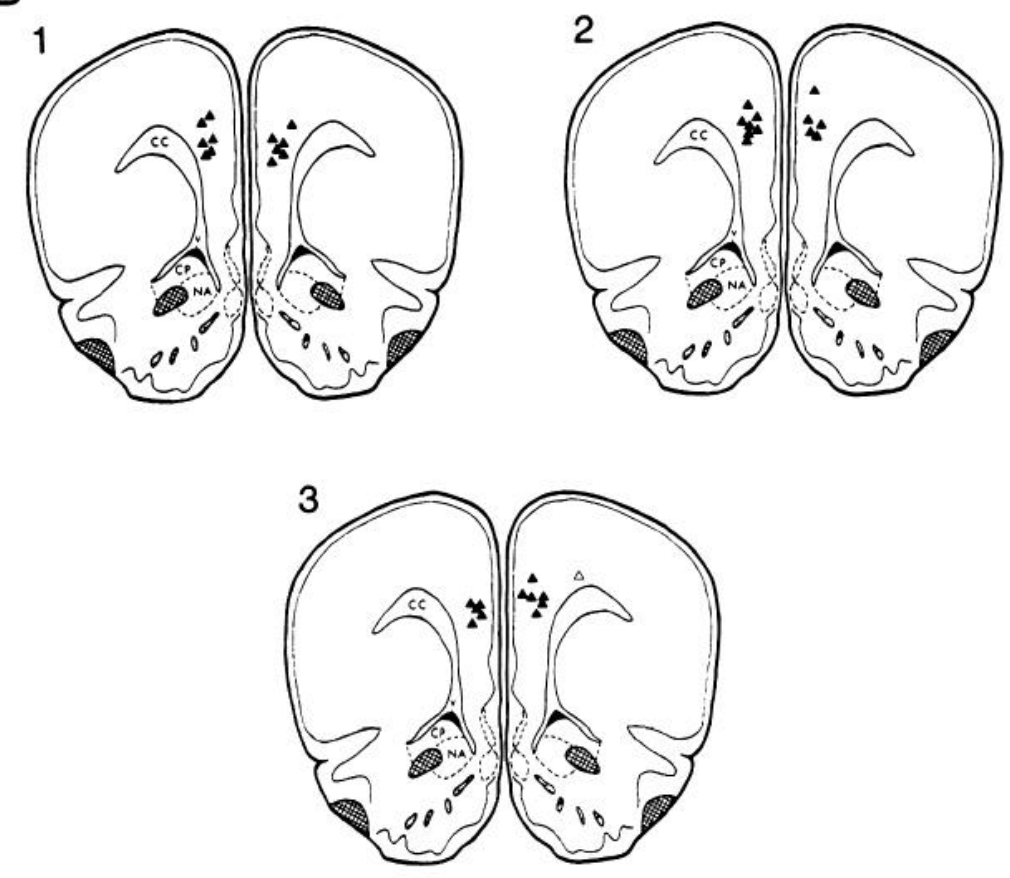

Figure 1. A, Representative photomicrograph illustrating unilateral injection site in the left medial prefrontal cortex of the rat. The position of the injection cannula is indicated by the black arrow. B, Diagrammatic representation of the cannulae placements in the medial prefrontal cortex $(\boldsymbol{\Delta})$ and lateral to the target area $(\Delta)$ in experiments 1-5. Cannulae were located $4.4-4.6 \mathrm{~mm}$ anterior to bregma. Abbreviations: $C C$, corpus callosum; $C P$, caudate nucleusputamen; $N A$, nucleus accumbens; $v$, lateral ventricle.
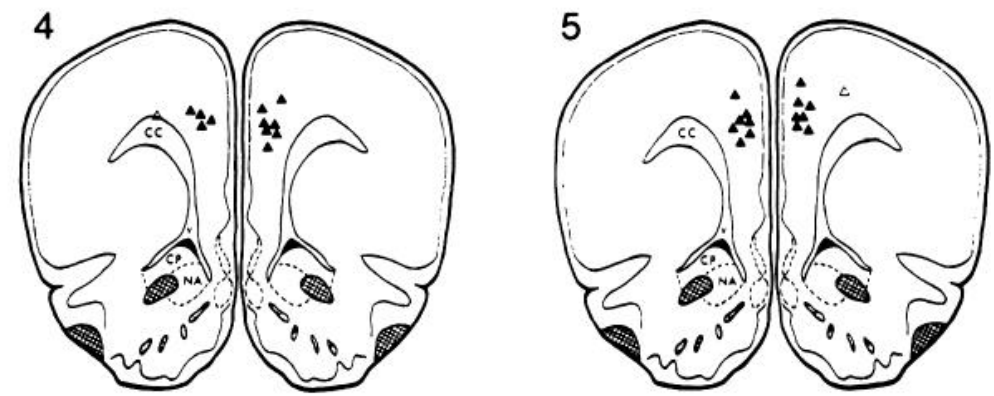

possibility that apparent drug effects resulted from diffusion of the drug from the medial prefrontal cortex to other DA terminal areas seems unlikely; the distance to the striatum is approximately $3 \mathrm{~mm}$ and $4 \mathrm{~mm}$ to the nucleus accumbens (Pellegrino et al., 1979), and previous reports have shown that a $1.0 \mu \mathrm{l}$ injection volume diffuses into a sphere of approximately $1 \mathrm{~mm}$ (Myers, 1974). To reduce the possibility of diffusion further, the volume injected was reduced to $0.5 \mu \mathrm{l}$ in the subsequent experiments.

Although the directional bias is consistent with a stimulant 
effect of cocaine, this effect could have been induced by a nondopaminergic mechanism. When injected peripherally, cocaine has local anesthetic properties that reportedly produce behavioral effects (Woolverton and Balster, 1979; Johanson, 1980; Spyraki et al., 1982; Morency and Beninger, 1986). In addition, as mentioned previously, cocaine inhibits the reuptake of NE (Langer and Enero, 1974) and 5-HT (Ross and Renyi, 1967), as well as the reuptake of DA (Snyder and Coyle, 1969; Heikkila et al., 1979). For these reasons, the possibility of a nondopaminergic effect was assessed with the pharmacologically specific agents procaine, a local anesthetic that does not share cocaine's potent central stimulant effects (Ritchie and Greene, 1980; Seeman and Spero, 1980), and SUL, a DA antagonist specific for the D-2 receptors (Tagliamonte et al., 1975; Elliott et al., 1977).

\section{Experiment 2: procaine-induced circling behavior}

The purpose of this study was to assess the possibility that unilateral microinjections of procaine, a local anesthetic not known to directly influence dopaminergic neurotransmission, would produce circling when injected into the medial prefrontal cortex. Procaine was injected in doses of 0 (saline), 10,100, and $1000 \mu \mathrm{g} / \mathrm{rat}$. The highest dose was greater than the highest dose of cocaine because procaine is a less potent local anesthetic (Goldstein et al., 1974).

Two $t$ tests for correlated measures were performed, one on the turning ratio data for the first and second no-injection scores and one for the saline-injection conditions. No significant differences were found in either case. Consequently, each of these conditions was combined for subsequent statistical analyses.

As depicted in Figure $2 B$, the mean turning ratios were between 0.5 and 0.6. A onc-factor, repcated-measures ANOVA did not reveal a significant main effect of dose. However, planned comparisons revealed a significant difference between the combined drug conditions $(10,100$, and $1000 \mu \mathrm{g} / \mathrm{rat})$ and the combined control conditions (no-injection and saline) $[F(1,11)=$ $5.12, p<0.05]$. This indicates a slight but significant ipsiversive bias. However, post hoc comparisons revealed that no individual procaine duse produced turning ratios significantly different from the saline condition (Fig. $2 B$ ).

The mean number $( \pm \mathrm{SEM})$ of total turns per session for each doses of procaine was as follows: no-injection, $14.5( \pm 1.4)$; saline, $16.8( \pm 2.4) ; 10 \mu \mathrm{g}, 15.6( \pm 2.0) ; 100 \mu \mathrm{g}, 15.9( \pm 1.7) ; 1000$ $\mu \mathrm{g}, 15.6( \pm 2.4)$. A one-factor, repeated-measures ANOVA did not reveal a significant dose effect.

These results suggest that the local anesthetic properties of cocaine did not contribute significantly to the contraversive bias observed in the first experiment. Indeed, it appeared that the temporary lesion induced by procaine resulted in a slight, but significant ipsiversive bias. Perhaps this slight ipsiversive bias would have been amplified by pretreatments with systemic (+)amphetamine. Such pretreatments have been used to amplify the ipsiversive bias induced by chronic unilateral frontal cortical lesions (Avemo et al., 1973; Glick and Greenstein, 1973) and by intrafrontocortical microinjections of DA antagonists (sec below).

\section{Experiments 3 and 4: sulpiride-induced circling behavior}

A previous study reported circling following intrafrontocortical microinjections of SUL in rats pretreated with systemic (+)amphetamine (Morency et al., 1985). SUL doses of 6.0, 12.0, and $24.0 \mu \mathrm{g}$ in $1 \mu \mathrm{l}$ induced ipsiversive circling, whereas its vehicle did not. The purpose of the present experiments was to
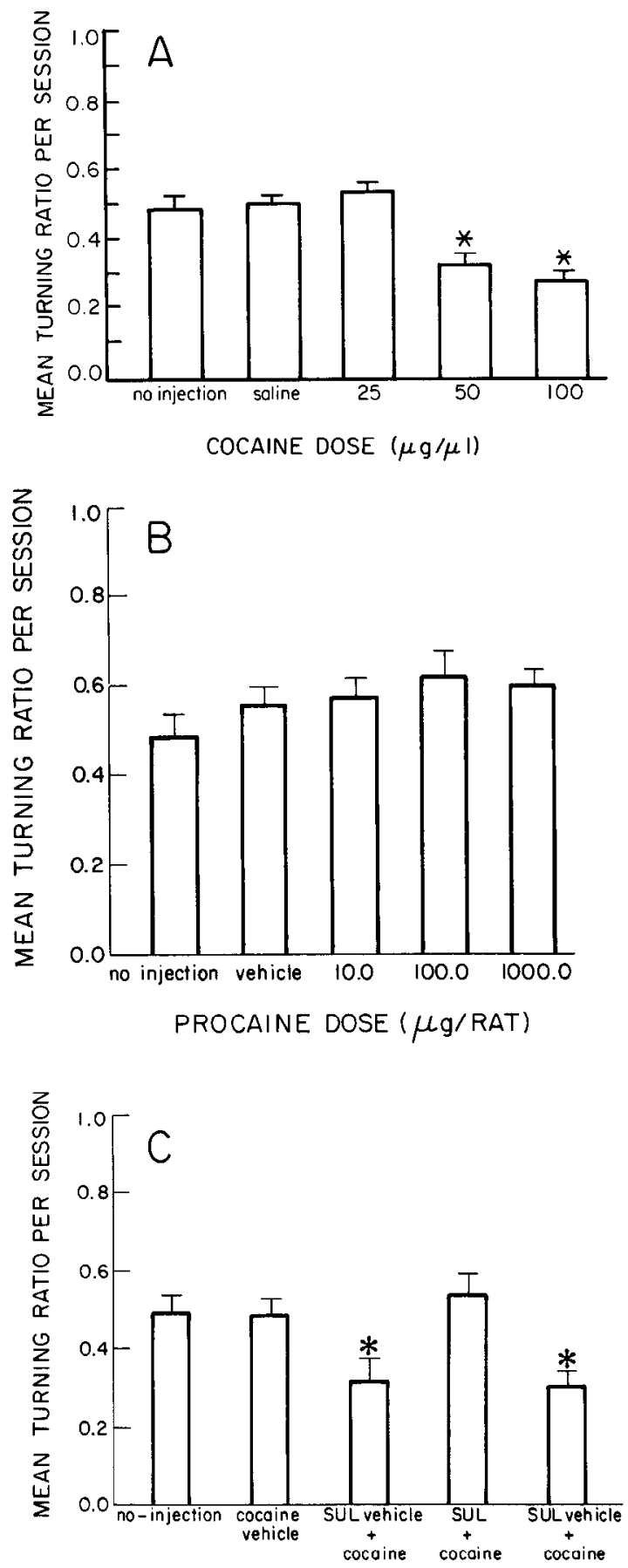

Figure 2. Mean turning ratio per session (ipsiversive turns/total turns) in cxpcriments $1(A), 2(B)$, and $5(C)$. Note that turning ratios less than 0.5 indicate tendencies for contraversive circling. Pairwise comparisons were made using post hoc analyses of variance: ${ }^{*} p<0.005$.

employ lower doses of SUL to test the possibility that it induces circling behavior in a dose-dependent manner. The experimental design was identical to experiments 1 and 2, except that all animals were pretreated with an injection of $(+)$-amphetamine $(1.5 \mathrm{mg} / \mathrm{kg}$, i.p.) $15 \mathrm{~min}$ prior to every test session to increase overall activity (Morency et al., 1985; Stewart et al., 1985). In experiment 3, SUL doses of 0 (vehicle), $0.1,1.0$, and $10.0 \mu \mathrm{g}$ were delivered in a volume of $0.5 \mu \mathrm{l}$.

The $2 t$ tests for correlated measures of the turning ratio data 

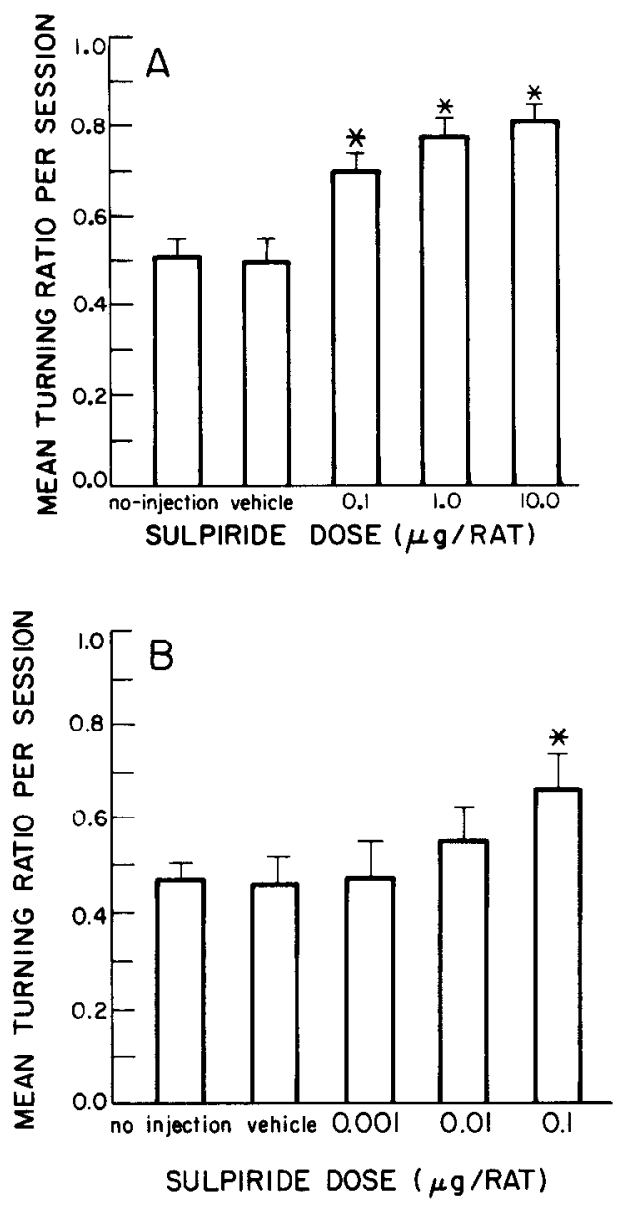

Figure 3. Mean turning ratio per session (ipsiversive turns/total turns) in experiments $3(A)$ and $4(B)$. Note that turning ratios greater than 0.5 indicate tendencies for ipsiversive circling. Pairwise comparisons were made using post hoc analyses of variance: ${ }^{*} p<0.005$.

for the first and second no-injection scores, as well as the first and second administration of vehicle, revealed no significant differences. Therefore, each animal's scores from these 2 sessions were combined for subsequent analyses.

SUL $(0.1,1$, and $10 \mu \mathrm{g})$ induced a circling bias ipsilateral to the side of the intrafrontocortical injections (Fig. $3 A$ ). A onefactor, repeated measures ANOVA confirmed the significance of this effect $[F(4,40)=13.97, p<0.0001]$. Planned comparisons revealed no significant difference between the no-injection and vehicle conditions. Finally, post hoc comparisons revealed that the $0.1,1$, and $10 \mu \mathrm{g}$ doses induced turning ratios significantly higher than the vehicle control (Fig. $3 A$ ).

The mean number $( \pm$ SEM) of total turns per session for each dose of SUL given to (+)-amphetamine-pretreated rats was as follows: no-injection, $43.5( \pm 4.9)$; vehicle, $46.8( \pm 4.2) ; 0.1 \mu \mathrm{g}$, $55.2( \pm 7.8) ; 1 \mu \mathrm{g}, 56.9( \pm 4.8) ; 10 \mu \mathrm{g}, 56.9( \pm 5.2)$. A one-factor, repeated-measures ANOVA revealed a significant dose effect $[F(4,40)=2.63, p<0.05]$.

Since all doses of SUL induced ipsilateral circling behavior, the experiment was repeated with lower doses: 0 (vehicle), 0.001 , 0.01 , and $0.1 \mu \mathrm{g}$ in $0.5 \mu \mathrm{l}$.

In experiment 4 , the first and second no-injection scores, as well as the first and second vehicle scores, were not significantly different. Consequently, they were combined for the ANOVA, which revealed a significant main effect of dose $[F(4,40)=4.74$, $p<0.005]$. Post hoc comparisons revealed that only the highest dose of SUL $(0.1 \mu \mathrm{g})$ produced significantly higher turning ratios than vehicle (Fig. $3 B$ ). Thus, SUL with systemic (+)-amphetamine produced dose-dependent ipsiversive circling.

The mean number $( \pm$ SEM) of total turns per session for animals receiving systemic ( + -amphetamine followed by central SUL was as follows: no-injection, $58.6( \pm 6.3)$; vehicle, 56.4 $( \pm 5.8) ; 0.001 \mu \mathrm{g}, 56.5( \pm 4.2) ; 0.01 \mu \mathrm{g}, 61.0( \pm 7.3) ; 0.1 \mu \mathrm{g}, 74.4$ $( \pm 6.6)$. Again, there was a significant dose effect $[F(4,40)=5.63$, $p<0.005]$.

\section{Experiment 5: effects of sulpiride on cocaine-induced circling behavior}

The results of experiments $2-4$ provide indirect evidence for the dopaminergic involvement in cocaine-induced circling behavior. More convincing evidence could be obtained by attempting to attenuate cocaine-induced circling with prior administration of the DA antagonist SUL. Thus, in experiment 5 , the schedule of drug administration was modified slightly. Animals were tested 7 times as follows: (1) no central injection; (2) central injection of cocaine's vehicle (saline); (3) central administration of SUL vehicle $(0.5 \mu \mathrm{l}) 15 \mathrm{~min}$ prior to central administration of cocaine (50.0 $\mu \mathrm{g}$ in $0.5 \mu \mathrm{l})$; (4) central administration of SUL $(1.0 \mu \mathrm{g}$ in $0.5 \mu \mathrm{l}) 15 \mathrm{~min}$ prior to central administration of cocaine $(50.0 \mu \mathrm{g}$ in $0.5 \mu \mathrm{l}) ;(5)$ replication of the third session; (6) replication of saline; (7) replication of no central injection.

As in previous experiments, the data for the 2 no-injection conditions and for the 2 vehicle conditions were combined since there were no significant differences between them.

SUL $(1.0 \mu \mathrm{g}$ in $0.5 \mu \mathrm{l})$ blocked the ipsilateral circling bias induced by intrafrontocortical injections of cocaine $(50.0 \mu \mathrm{g}$ in $0.5 \mu \mathrm{l}$ ) when administered $15 \mathrm{~min}$ prior to the cocaine injection, whereas its vehicle did not (Fig. 2C). A one-factor, repeatedmeasures ANOVA indicated a significant drug treatment effect $[F(4,52)=21.49, p<0.0001]$. Planned comparisons revealed no significant difference between the no-injection and the saline conditions. In addition, the turning ratios produced in the first and second sessions with SUL vehicle followed by cocaine were significantly lower than those produced by the SUL followed by cocaine condition $[F(1,13)=54.43$ and $39.13, p<0.0001$, respectively]. Finally, post hoc comparisons revealed that the turning ratios for both sessions with SUL vehicle followed by cocaine were significantly different from the saline condition (Fig. 2C).

The mean number $( \pm$ SEM) of total turns per session for each drug treatment was as follows: no-injection, $13.8( \pm 1.5)$; saline, 14.9 ( \pm 1.3 ); SUL vehicle followed by cocaine, 20.1 ( \pm 1.6$)$; SUL followed by cocaine, $13.6( \pm 1.7)$; SUL vehicle followed by cocaine, $19.1( \pm 2.3)$. A one-factor, repeated-measures ANOVA revealed that the means differed significantly $[F(4,52)=4.95$, $p<0.003$ ].

\section{Discussion}

The strong tendency for contraversive circling observed in experiment 1 following the 50 and $100 \mu \mathrm{g}$ doses suggests that cocaine produced an ipsilateral enhancement of locomotor activity. The lack of effect of the local anesthetic procaine in experiment 2 and the blockade of cocaine-induced circling behavior by the DA antagonist SUL in experiment 5 suggest that the cocaine-produced increase in contraversive circling was mediated by DA. 
Absence of significant differences between the first and second saline sessions in experiments $1-5$ illustrates the acute nature of the manipulations of this experiment as the animals returned to baseline turning ratios after the drug sessions. Furthermore, as saline scores were not significantly different from the noinjection scores, it is clear that saline did not induce a directional bias. The possibility that apparent drug effects resulted from progressive damage due to repeated central injections seems unlikely, as order of dose or treatment was counterbalanced, yet a significant dose effect occurred in experiments 1,4 and 5 .

The possibility of diffusion of the drug from the frontal cortex to the striatum or the nucleus accumbens also seems unlikely. It has been shown that a $1.0 \mu \mathrm{l}$ injection volume diffuses into a sphere of approximately $1 \mathrm{~mm}$ (Myers, 1974). In the rat brain a distance of at least $3 \mathrm{~mm}$ separates the medial prefrontal cortex and these areas. In addition, when the injection volume was reduced to $0.5 \mu \mathrm{l}$, ipsiversive circling behavior was induced by intrafrontocortical injections of $0.1,1.0$, and $10.0 \mu \mathrm{g} \mathrm{SUL}$ in $(+)$-amphetamine pretreated rats.

As previously mentioned, it has been suggested that frontal cortical DA normally inhibits locomotor activity as bilateral or unilateral 6-OHDA lesions of this area produce hyperactivity after a period of 7-10 d (Pycock et al., 1980a; Robinson and Stitt, 1981; Joyce ct al., 1983). Providing further support for this hypothesis, Tassin et al. (1978) reported a high correlation between the increase in locomotor activity and the decrease in frontal cortical DA $30 \mathrm{~d}$ following bilateral electrolytic destruction of the ventral tegmental area. However, biochemical data have shown increased levels of DA function in the nucleus accumbens and striatum 4 weeks subsequent to frontal cortical DA denervation (Pycock et al., 1980b). Thus, the hyperactivity may reflect these time-dependent, compensatory subcortical changes, demonstrating cortical regulation of subcortical DA function.

This interpretation is not inconsistent with studies of lesions of frontal cortex. Unilateral ablation of the frontal cortex of rats has been shown to induce rotational behavior (Avemo et al., 1973; Glick and Greenstein, 1973). At early postoperative intervals (1-7 d), these animals circled ipsilaterally both spontaneously and after systemic administration of amphetamine, the intact side being the locus of greater DA activity. At later times (15-30 d), contraversive rotation was observed in response to systemic amphetamine (Avemo et al., 1973; Glick and Greenstein, 1973). Although the damage induced by ablation is nonspecific, these data are also compatible with those of Pycock et al. (1980b). It is possible that the ipsiversive circling was in response to frontal cortical loss, whereas the shift to contraversive circling reflected the subcortical compensatory changes and, as such, is suggestive of frontal cortical mediation of subcortical function.

Employing acute unilateral frontal cortical DA manipulations to avoid lesion-induced compensatory changes in subcortical DA systems, we have observed ipsiversive turning following injections of the DA antagonists metoclopramide (Stewart et al., 1985), SUL (experiments 3 and 4; and Morency et al., 1985), and $c i s$-flupenthixol (unpublished observations) and contraversive turning following $(+)$-amphetamine, LY 141865 (Stewart et al., 1985), and, now, cocaine (experiments 1 and 5). Thus, our results suggest that frontal cortical DA has an excitatory influence on locomotor control.

The results of the present study provide support for a frontal cortical contribution to the stimulant effect of cocaine. It has been demonstrated, however, that the frontal cortex is not necessary for circling, as bilaterally decorticate rats with unilateral 6-OHDA lesions of the substantia nigra showed only a small reduction in drug-induced circling (Crossman et al., 1977). It is important to note that the circling observed in the present study was not a tight nose-to-tail posture (see Pycock, 1980), but a directional bias. Thus, the frontal cortex may have a modulatory function in locomotor activity, serving as a higher level of control, while not precluding the ability of lower levels to exert independent control.

\section{References}

Ahn, H. S., R. K. Mishra, C. Demirjian, and M. H. Makman (1976) Catecholamine-sensitive adenylate cyclase in frontal cortex of primate brain. Brain Res. 116: 437-454.

Anden, N. E., A. Carlsson, and J. Haggendal (1969) Adrenergic mechanisms. Annu. Rev. Pharmacol. 9: 119-134.

Anden, N. E., S. G. Butcher, H. Corrodi, K. Fuxe, and U. Ungerstedt (1970) Receptor activity and turnover of dopamine and noradrenaline after neuroleptics. Eur. J. Pharmacol. 11: 303-314.

Avemo, A., S. Antelman, and U. Ungerstedt (1973) Rotational behaviour after unilateral frontal cortex lesions in the rat. Acta Physiol. Scand. Suppl. 396 84: 77.

Beninger, R. J. (1983) The role of dopamine in locomotor activity and learning. Brain Res. Rev. 6: 173-196.

Bindra, D. (1978) How adaptive behavior is produced: A perceptualmotivational alternative to response-reinforcement. Behav. Brain Sci. 1: 41-91.

Carter, C. J., and C. J. Pycock (1978) Studies on the role of catecholamines in the frontal cortex. Br. J. Pharmacol. 62: 402.

Costall, B., and R. J. Naylor (1975) The behavioural effects of dopamine applied intracerebrally to areas of the mesolimbic system. Eur. J. Pharmacol. 32: 87-92.

Costall, B., C. D. Marsden, R. J. Naylor, and C. J. Pycock (1977) Stereotyped behavior patterns and hyperactivity induced by amphetamine and apomorphine after discrete 6-hydroxydopamine lesions of extrapyramidal and mesolimbic nuclei. Brain Res. 123: 89111.

Crossman, A. R., M. A. Sambrook, S. W. Gergies, and P. Slater (1977) The neurological basis of motor asymmetry following unilateral 6-hydroxydopamine brain lesions in the rat: The effect of motor decortication. J. Neurol. Sci. 34: 407-414.

Donovick, P. J. (1974) A metachromatic stain for neural tissue. Stain Technol. 49: 49-51.

Elliott, P. N. C., P. Jenner, G. Huizing, C. D. Marsden, and R. Miller (1977) Substituted benzamides as cerebral dopamine antagonists in rodents. Neuropharmacology 16: 333-342.

Fields, J. Z., T. D. Reisine, and H. I. Yamamura (1977) Biochemical demonstration of dopaminergic receptors in rat and human brain using $\left[{ }^{3} \mathrm{H}\right]$ spiroperidol. Brain Res. 136: 578-584.

Glick, S. D., and S. Greenstein (1973) Possible modulating influence of frontal cortex on nigro-striatal function. Br. J. Pharmacol. 49: 316321.

Goeders, N. E., and J. E. Smith (1983) Cortical dopaminergic involvement of cocaine reinforcement. Science 221: 773-775.

Goldstein, A., L. Aronow, and S. M. Kalman (1974) Principles of Drug Actions: The Basis of Pharmacology, 2nd ed., Wiley, New York.

Heikkila, R. E., F. S. Cabbat, L. Manzino, and R. C. Duvoisin (1979) Rotational behavior induced by cocaine analogs in rats with unilateral 6-hydroxydopamine lesions of the substantia nigra: Dependence upon dopamine uptake inhibition. J. Pharmacol. Exp. Ther. 211: 189-194.

Jackson, D. M., N. E. Anden, and A. Dahlstrom (1975) A functional effect of dopamine in the nucleus accumbens and in some other dopamine-rich parts of the rat brain. Psychopharmacologia 45: 139 149.

Johanson, C. E. (1980) The reinforcing properties of procaine, chloroprocaine and proparacaine in rhesus monkeys. Psychopharmacology 67: 189-194.

Joyce, E. M., L. Stinus, and S. D. Iversen (1983) Effect of injections of 6-OHDA into either nucleus accumbens septi or frontal cortex on spontaneous and drug-induced activity. Neuropharmacology 22: 11411145. 
Joyce, J. N. (1983) Multiple dopamine receptors and behavior. Neurosci. Biobehav. Rev. 7: 227-256.

Langer, S. Z., and M. A. Enero (1974) The potentiation of responses to adrenergic nerve stimulation in the presence of cocaine: Its relationship to the metabolic fate of released norepinephrine. J. Pharmacol. Exp. Ther. 191: 431-443.

Morency, M. A., and R. J. Beninger (1987) Dopaminergic substrates of cocaine-induced place conditioning. Brain Res. 399: 33-41.

Morency, M. A., R. J. Stewart, and R. J. Beninger (1985) Effects of unilateral microinjections of sulpiride into the medial prefrontal cortex on circling behavior of rats. Prog. Neuro-Psychopharmacol. Biol. Psychiatr. 9: 735-738.

Myers, R. D. (1974) Handbook of Drug and Chemical Stimulation of the Brain: Behavioral, Pharmacological and Physiological Aspects, Van Nostrand, New York.

Myers, R. D., and F. Mora (1977) In vivo neurochemical analysis, by push-pull perfusion, of the mesocortical dopaminergic system of the rat during self-stimulation. Brain Res. Bull. 2: 105-122.

Pellegrino, L. J., A. S. Pellegrino, and A. J. Cushman (1979) A Stereotaxic Atlas of the Rat Brain, Plenum, New Y.ork.

Pijnenberg, A. J., W. M. Honig, J. A. van der Heyden, and J. M. van Rossum (1976) Effects of chemical stimulation of the mesolimbic dopamine system upon locomotor activity. Eur. J. Pharmacol. 35 . 45-58.

Pycock, C. J. (1980) Turning behaviour in animals. Neuroscience 5: 461-514.

Pycock, C. J., C. J. Carter, and R. W. Kerwin (1980a) Effect of 6-hydroxydopamine lesions of the medial prefrontal cortex on neurotransmitter systems in subcortical sites in the rat. J. Neurochem. 34: 91-99.

Pycock, C. J., R. W. Kerwin, and C. J. Carter (1980b) Effects of lesions of cortical dopamine terminals on subcortical dopamine receptors in rats. Nature 286: 74-77.

Ritchie, J. M., and N. M. Greene (1980) Local anesthetics. In The Pharmacological Basis of Therapeutics, A. Goodman Gilman, L. S. Goodman, and A. Gilman, eds., pp. 300-320, MacMillan, Toronto. Robinson, R. G., and T. G. Stitt (1981) Intracortical 6-hydroxydo- pamine induces an asymmetrical behavioral response in the rat. Brain Res. 213: 387-395.

Ross, S. B., and A. L. Renyi (1967) Accumulation of tritiated 5-hydroxytryptamine in brain slices. Life Sci. 6: 1407-1415.

Saldate, M. C., and F. Orrego (1977) Electrically induced release of $\left[{ }^{3} \mathrm{H}\right]$ dopamine from slices obtained from different rat brain cortex regions. Evidence for a widespread dopaminergic innervation of the neocortex. Brain Res. 130: 483-494.

Seeman, P., and L. Spero (1980) Local anaesthetics. In Principles of Medical Pharmacology, P. Seaman, E. M. Sellers, and W. H. E. Roschlau, eds., pp. 211-216, The University of Toronto Press, Toronto.

Snyder, S. H., and J. T. Coyle (1969) Regional difference in $\left[{ }^{3} \mathrm{H}\right]-$ norepinephrine and $\left[{ }^{3} \mathrm{H}\right]$-dopamine uptake into rat brain homogenate. J. Pharmacol. Exp. Ther. 165: 78-86.

Spyraki, C., H. C. Fibiger, and A. G. Phillips (1982) Cocaine-induced place preference conditioning: Lack of effects of neuroleptics and 6-hydroxydopamine lesions. Brain Res. 253: 195-203.

Stewart, R. I., M. A. Morency, and R. J. Beninger (1985) Differential effects of intrafrontocortical microinjections of dopamine agonists and antagonists on circling behavior of rats. Behav. Brain Res. 17: $67-72$.

Tagliamonte, A., G. De Montis, M. Olianas, L. Vargiu, G. U. Corsini, and G. L. Gessa (1975) Selective increase of brain dopamine synthesis by sulpiride. J. Neurochem. 24: 707-710.

Tassin, J. P., L. Stinus, H. Simon, G. Blanc, A. M. Thierry, M. Le Moal, B. Cardo, and J. Glowinski (1978) Relationship between the locomotor hyperactivity induced by AlO lesions and the destruction of the frontocortical dopaminergic innervation in the rat. Brain Res. 141: 267-281.

Thierry, A. M., G. Blanc, A. Sobel, L. Stinus, and J. Glowinski (1973) Dopaminergic terminals in the rat cortex. Science 182:499-501.

Willner, P. (1983) Dopamine and depression: A review of recent evidence. II. Theoretical approaches. Brain Res. Rev. 6: 225-236.

Woolverton, W. L., and R. L. Balster (1979) Reinforcing properties of some local anesthetics in rhesus monkeys. Pharmacol. Biochem. Behav. 11: 669-672. 